Provided for non-commercial research and education use. Not for reproduction, distribution or commercial use.

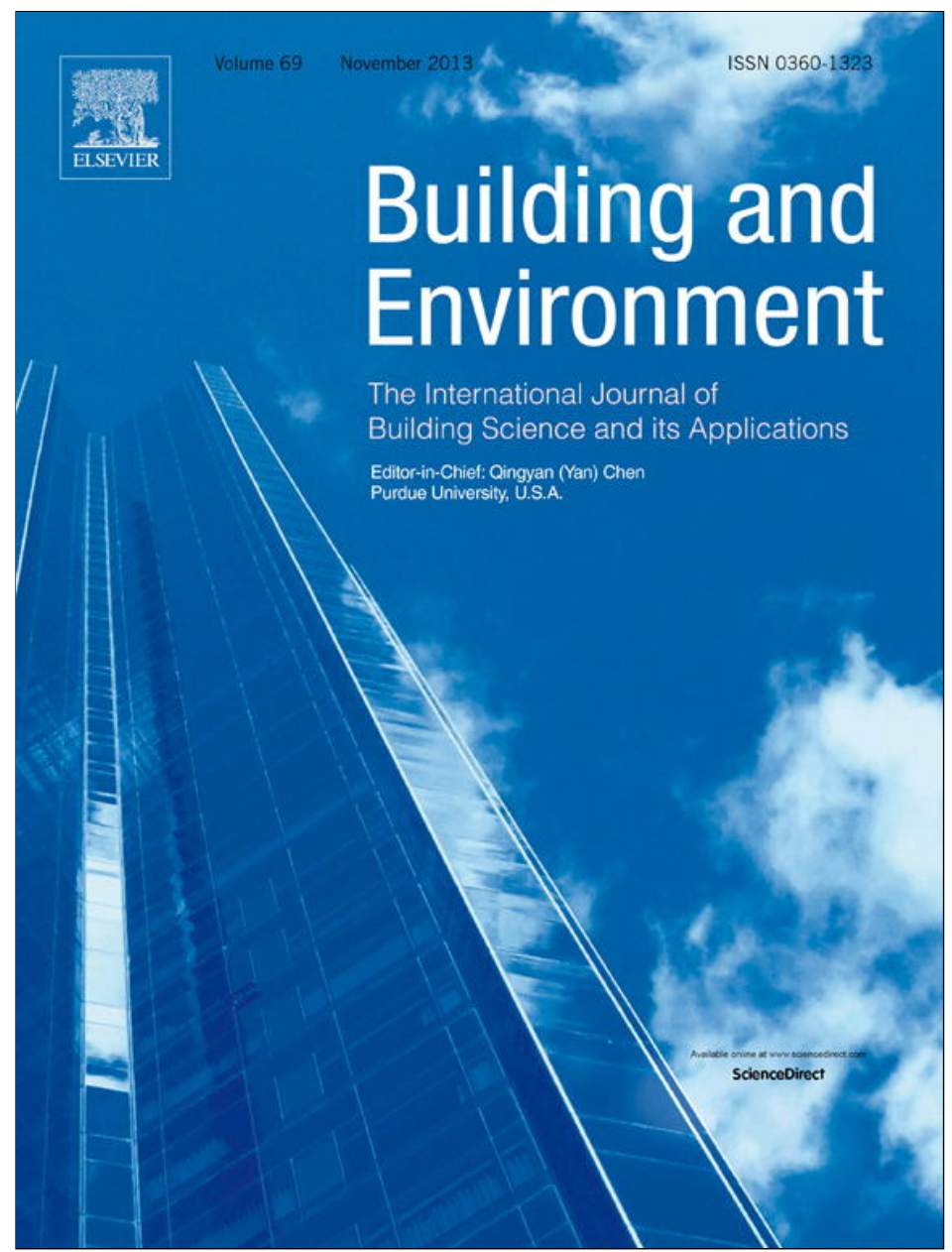

This article appeared in a journal published by Elsevier. The attached copy is furnished to the author for internal non-commercial research and education use, including for instruction at the authors institution and sharing with colleagues.

Other uses, including reproduction and distribution, or selling or licensing copies, or posting to personal, institutional or third party websites are prohibited.

In most cases authors are permitted to post their version of the article (e.g. in Word or Tex form) to their personal website or institutional repository. Authors requiring further information regarding Elsevier's archiving and manuscript policies are encouraged to visit:

http://www.elsevier.com/authorsrights 


\title{
The influence of ventilation systems on domestic gas appliances: An experimental study
}

\author{
M. Pinto ${ }^{\mathrm{a}, *}$ J. Viegas ${ }^{\mathrm{b}}$ \\ ${ }^{a}$ School of Technology Er Management, Viseu Polytechnic Institute, Campus de Repeses, 3504-510 Viseu, Portugal \\ ${ }^{\mathrm{b}}$ National Laboratory of Civil Engineering, Av. do Brasil, 101, 1700-066 Lisboa, Portugal
}

\section{A R T I C L E I N F O}

\section{Article history:}

Received 3 June 2013

Received in revised form

12 July 2013

Accepted 14 July 2013

\section{Keywords:}

Air permeability

Gas appliances

Dwellings

Ventilation systems

Reverse flow

\begin{abstract}
A B S T R A C T
Ventilation systems play an important role in the energy consumption of heating and cooling, defining hygrothermal conditions and air quality of dwellings. Among other functions, they are absolutely necessary to ensure oxygen levels needed for household combustion appliances.

In Portugal in multifamily housing and with natural ventilation systems, installing a mechanical exhaust fan in every kitchen (decentralized ventilation) is common. In this paper, the impact of such a device is evaluated regarding the performance of a water heating appliance for heating the indoor environment or for domestic hot water (B-type gas appliance usually installed in the kitchen). The combination of natural or mechanical ventilation in the kitchen with the natural exhaust of the gas appliance's combustion products were tested as well as the evaluation of critical conditions that lead to stopping the gas appliance safely or to reversing the combustion products in the respective exhaust duct. One of the main conclusions to be drawn is that in the case of mechanical exhaust in the kitchen simultaneously with the natural exhaust of the gas appliance's combustion products, the kitchen's exterior air inlet is a key device for ensuring proper exhaust of combustion products. In extreme situations, reduced air intake by other means or high extraction flows, they can prevent safely stopping the appliance or even reversing the flow of the combustion products. For this purpose, the maximum flow of mechanical exhaust should also be limited.
\end{abstract}

(c) 2013 Elsevier Ltd. All rights reserved.

\section{Introduction}

The use of type B [1] gas combustion appliances can contaminate the indoor environment with pollutants, reducing indoor air quality due to insufficient air intake or inadequate combustion product exhaust. These devices are characterized by the intake of new air required for combustion from the indoor environment and for combustion product exhaust through ducts. The contamination of indoor air may occur in this type of device when the internal pressure is lower than the pressure in the exhaust ducts. The gradual reduction of oxygen content in the new air intake device leads to inefficient combustion, which increases the release of toxic combustion products, including carbon monoxide (CO). If the combustion appliances are equipped with safety devices (e.g. $\mathrm{B}_{11 \mathrm{BS}}$ - the letters "BS" in the index indicate safety in case of obstruction of the duct), inadequate exhaust of the combustion products is

\footnotetext{
* Corresponding author. Tel.: +351 232480 500; fax: +351232424 651

E-mail address: mpinto@estv.ipv.pt (M. Pinto).
}

detected (this condition potentially causes contamination of indoor air), the gas supply is cut off and the device stops working. In general, this device operates by detecting the increase in temperature associated with the accumulation of combustion products in the evacuation draught diverter of the apparatus. In this case, safety is assured, but the availability of the appliance in terms of operation may be greatly reduced. In dwellings subject to the natural actions of wind and buoyancy, the conditions for such unfavorable differences in pressure between indoor and outdoor conditions will hardly occur. It is more likely to occur due to the incorrect use of mechanical extraction devices, without regards for the requirements of natural ventilation systems.

As part of a research project, it was possible to evaluate the exhaust performance of combustion products in two naturally ventilated dwellings and with a mechanical exhaust fan installed in the kitchen - the interaction of ventilation between the two dwellings was also analyzed. The aim of this article is to continue to present the previously published results [2], namely some tests with the combination of natural ventilation and mechanical ventilation in spaces interconnected by ducts that may lead to 


\begin{tabular}{|ll|}
\hline Nomenclature \\
ACH & air change rate, $\left[\mathrm{h}^{-1}\right]$ \\
$h$ & height of an air inlet or window, $[\mathrm{m}]$ \\
$\mathrm{MV}$ & mechanical ventilation \\
$\mathrm{NV}$ & natural ventilation \\
$n$ & air change rate at $50 \mathrm{~Pa},\left[\mathrm{~h}^{-1}\right]$ \\
$q$ & air flow rate, $\left[\mathrm{m}^{3} / \mathrm{h}\right]$ \\
$T$ & temperature, $\left[{ }^{\circ} \mathrm{C}\right]$ \\
$w$ & width of an air inlet or window, $[\mathrm{m}]$ \\
& \\
Greek symbols \\
$\Delta p$ & pressure difference, $[\mathrm{Pa}]$ \\
$\zeta$ & pressure loss coefficient, $[-]$ \\
$\phi$ & diameter, [mm] \\
\hline
\end{tabular}

dangerous situations when type B gas water heating appliances are used. The experimental results included wind speed and in ducts as well as temperatures (within the ducts, in the dwellings and outdoors). Based on these data, estimates were made of the air flow rates. The problems that can occur due to this unsuitable combination of ventilation modes were demonstrated. In particular, it was possible to assess the problems that may arise when the gas water heater is running simultaneously with the kitchen's mechanical ventilation where the gas appliance is installed. The requirements that provide adequate ventilation for combustion products are also discussed.

\section{Indoor air quality and ventilation systems}

\subsection{Exhaust from combustion appliances}

Despite being long-standing, concerns about the impacts on public health due to exposure to $\mathrm{CO}$ produced by gas appliances are still current [3]. Most accidents are due to insufficient air intake or the poor condition of gas appliance installation and exhaust. For example, exhaust ducts serve simultaneously for the gas heater and the stove's mechanical exhaust [4]. Research has shown that the air intake has a predominant effect on kitchen ventilation and the exhaust duct obstruction limits ventilation flow. However, air intake is essential in buildings with reduced air permeability [5]. In addition, it has been shown that with mechanical extraction in the kitchen, air intake has to be much higher [6].

All gas appliances in the kitchen need a certain air flow to feed the chemical reaction of combustion. This air flow is called "combustion air." Safety issues may arise when the air intake is not sufficient or when the flow through the appliance and the exhaust ducts to the outside does not occur properly. In the second situation, reverse flow occurs when the combustion appliance is not capable of maintaining an upward flow causing combustion gases to come into the indoor air [7].

According to the document PD CEN/TR 1749 [1], the classification of gas appliances according to the method of evacuation of the combustion products is:

- type A: "unconnected" appliances" (e.g. stoves). These devices don't have a duct for the exhaust of the combustion product. They should preferably be evacuated in their vicinity [8];

- type B: "connected appliances" (e.g. boilers, water heaters). In these devices the combustion products are exhausted through ducts and the intake air is captured from the room where they are installed;
- type C: "sealed appliances" (e.g. boilers). These devices have "isolated" combustion, which means the intake air and exhaust gases do not mix with indoor air.

In Portugal naturally ventilated devices are common (type B). In these devices the exhaust is performed through a vertical duct. Mechanical ventilation of the kitchen, which is common in Portugal, can cause depressions in the room where the combustion device is installed, increasing the likelihood of reverse flow. Therefore, in these cases, the requirements of ventilation systems should include safeguards to avoid this [7].

The poor supply of intake air or reverse flow can cause combustion products to be released into the room. Combustion products are harmful to health, especially nitrogen oxides (NOx) and CO. $\mathrm{CO}$ is formed by incomplete combustion when the oxygen supplied is insufficient.

\subsection{Indoor air quality in dwellings}

Generally speaking, provided that the outdoor air quality is acceptable, one can obtain good indoor environment quality using adequate ventilation of these spaces. The design and implementation of ventilation systems in dwellings will need to take the sources of pollution into account in order to proceed to evacuating pollutants, preferably near their source, thus avoiding contaminating indoor air. For example, in the case of type B and C [1] gas combustion appliances for domestic use, combustion products should be discharged directly outdoors. In the case of type A appliances, they should preferably be evacuated in their vicinity [8]. Ideally, the combustion products must be exhausted directly outdoors without mixing significantly with the indoor air. Currently, for type A gas appliances mechanical ventilators are used to extract combustion products, even though their uptake efficiency is generally about 60\% [7].

Indoor air quality should be ensured in order to prevent dangerous pollutants from reaching concentrations that could endanger occupants' health (health criterion = safety criterion), while maintaining a pleasant environment (sensory criterion = comfort criterion). As for the health criterion, limit values for pollutants are currently established as a function of the time occupants spend in the contaminated environment.

The coexistence of both criteria is important because there are substances that can only be assessed by one of them. For example, $\mathrm{CO}$ is a gas which is fatal at relatively high concentrations, and because it is colorless and odorless, it is not detectable by humans. In this case, the criterion of imposed limits is appropriate.

To assess contaminants inside dwellings, large scale studies have been conducted [9]. In addition, in the USA [10] and Europe [11] combustion products, particularly $\mathrm{PM}_{2.5}$ particles (particulate matter with an aerodynamic diameter below $2.5 \mu \mathrm{m}$ ) and $\mathrm{CO}$, as well as formaldehyde $(\mathrm{HCOH})$, have been identified as the contaminants which pose the greatest health hazard inside dwellings. To this end, from a recent survey in 16 European countries, only six had pollutant limits for indoor non-industrial environments [12]. These six countries had only limits for two pollutants in common: $\mathrm{CO}$ and $\mathrm{HCOH}$. Table 1 presents the countries under study and the respective limits. It also presents the World Health Organization (WHO) and Environmental Protection Agency (EPA) limits as a benchmark.

It appears that, generally speaking, the limits in the various countries are below the WHO limit. However, for $\mathrm{PM}_{2.5}$ European countries do not have requirements as of yet. Information on carbon dioxide production $\left(\mathrm{CO}_{2}\right), \mathrm{CO}$ and NOx from domestic tobacco, ovens and stoves can be found in Ref. [16]. 
Table 1

Indoor pollutant limits for dwellings (adapted from Refs. [12-15]).

\begin{tabular}{lcccccc}
\hline & WHO & USA (EPA) & Finland & Lithuania & Norway & Portugal \\
\hline $\mathrm{PM}_{2.5}\left[\mu \mathrm{g} / \mathrm{m}^{3}\right]$ & $25^{\mathrm{d}}$ & $35^{\mathrm{d}}$ & & & & \\
$\mathrm{CO}\left[\mathrm{mg} / \mathrm{m}^{3}\right]$ & $10^{\mathrm{c}}$ & $10.3^{\mathrm{c}}$ & 8 & 3 & $10^{\mathrm{c}}$ & 12.5 \\
$\mathrm{NO}_{2}\left[\mu \mathrm{g} / \mathrm{m}^{3}\right]$ & $200^{\mathrm{b}}$ & $188^{\mathrm{b}}$ & & 40 & $100^{\mathrm{b}}$ & $6^{\mathrm{a}}$ \\
$\mathrm{HCOH}\left[\mu \mathrm{g} / \mathrm{m}^{3}\right]$ & $100^{\mathrm{a}}$ & & 50 & 10 & $100^{\mathrm{a}}$ & 100 \\
\hline
\end{tabular}

a 30 min average.

b $1 \mathrm{~h}$ average.

c $8 \mathrm{~h}$ average.

d $24 \mathrm{~h}$ average.

\subsection{Ventilation systems}

In residential buildings ventilation systems are essentially intended to ensure indoor air quality, provide new air for combustion appliances and ensure the extraction of combustion products. This ventilation should be provided under conditions of comfort and safety while minimizing energy consumption.

Outdoor air intake is required to safeguard occupant health and has the following functions [17]:

- to dilute and remove of pollutants, including substances emitted by furniture, building materials, cleaning products, odors, $\mathrm{CO}_{2}$ derived from human metabolism and water vapor. These pollutants normally have low emission rates but continuous and diffuse;

- to dilute and remove specific pollutants from identified sources such as odors from bathrooms, cooking, steam from cooking or baths, tobacco smoke and combustion products. These pollutants usually have relatively high emission rates but of short duration and specific location;

- to supply oxygen for occupant breathing;

- to control indoor humidity due to personal hygiene (bathing), washing and drying dishes and laundry, etc.;

- to supply air for combustion appliances.

The upper limit of ventilation rates, if any exists, is established, taking into account criteria for energy conservation. To establish the lower limit, there are currently two methods (adapted from Refs. [18,19]):

- prescriptive method: defining a ventilation air flow rate of new air, usually expressed per unit of area, unit of volume (this definition gives rise to the air change rates parameter $-\mathrm{ACH}$ $\left[\mathrm{h}^{-1}\right]$ ) or per person. In addition, there may be other ways to prescribe for specific situations such as air flow rate of new air required for combustion appliances. This is usually expressed as a function of the device's power, or the installation of a device which can ensure the required air flow rate, characterized by the size of the area of an air inlet to be permanently or controllably open for natural ventilation;

- demand method: defining the limits of the concentration of potential pollutants or odors so as to limit maximum exposure.

Given the difficulties in applying the demand method a simplified methodology was recently adopted in international standardization (with a prescriptive character, although more detailed). New air flow rate type-values are adopted to prevent pollution due to the building (proportional to the area) and occupants (proportional to the respective number). Adopting ventilation categories is simultaneously used to depending on the number of dissatisfied people [20].

In practice, prescribed ventilation rates $\left(\mathrm{ACH}\left[\mathrm{h}^{-1}\right]\right)$ are used for any dwelling or air flow rates for specific rooms, based on their occupation or on activities that take place in them - some authors conclude that mechanical extraction is beneficial in kitchens with gas appliances to reduce the concentration of pollutants in the room $[21,22]$. In the kitchen, the maximum extraction flow must be the value which corresponds to the proper evacuation of products from cooking and operating any existing gas appliances in this room [23]. Often, the maximum air flow rate is obtained using an intermittent peak value not required for regular ventilation of the dwelling. Table 2 summarizes the main requirements for ventilation for kitchens in dwellings in several countries. The same table indicates an example of the air flow rate obtained by following these criteria for a house with 3 bedrooms and 4 people, a $30 \mathrm{~m}^{3}$ kitchen and exhaustion at the stove (a $1 \mathrm{~m}$ wide stove).

Table 2 shows that with the exception of Greece the maximum extraction air flow rate in the kitchen is found between approximately $100 \mathrm{~m}^{3} / \mathrm{h}$ and $200 \mathrm{~m}^{3} / \mathrm{h}$.

Intermittent ventilation systems (mechanical ventilation driven according to the needs of removing pollutants) require higher air flow rates as shown in Table 2 for the particular case of the USA. In

Table 2

Summary of maximum exhaust ventilation prescriptions in the kitchen (adapted from Refs. [7,8,23-25]).

\begin{tabular}{|c|c|c|}
\hline Country [source] & Maximum air flow rate in the kitchen & Example \\
\hline France [Arreté du 24.3.82] & $75-135 \mathrm{~m}^{3} / \mathrm{h}$ (inter.; depends on no. of rooms) & $105 \mathrm{~m}^{3} / \mathrm{h}$ \\
\hline Germany [DIN 1946, Part6; DIN 18017; VDI 2088] & Purge: $200 \mathrm{~m}^{3} / \mathrm{h}(>12 \mathrm{~h}$ occupation/day) & $200 \mathrm{~m}^{3} / \mathrm{h}$ \\
\hline UK [Building Regs. Approved, Doc. F] & $108 \mathrm{~m}^{3} / \mathrm{h}$ adjacent to stove, $216 \mathrm{~m}^{3} / \mathrm{h}$ if located elsewhere (inter.; ex.) & $108 \mathrm{~m}^{3} / \mathrm{h}$ \\
\hline Greece [Greek Legislative Framework Document] & $50-85 \mathrm{~m}^{3} / \mathrm{h} / \mathrm{p}$ (recommend) & $200-340 \mathrm{~m}^{3} / \mathrm{h}$ \\
\hline Italy [Standard UNI 10339] & $4 \mathrm{ACH}(\mathrm{ex})$. & $120 \mathrm{~m}^{3} / \mathrm{h}$ \\
\hline $\begin{array}{l}\text { USA [ASHRAE 62.2: } 2013 \text {, applicable to dwellings } \\
\text { or multifamily buildings up to three storeys] }\end{array}$ & $180 \mathrm{~m}^{3} / \mathrm{h}$ (inter.; MV), $5 \mathrm{ACH}$ (cont.; NV) ${ }^{\mathrm{a}}$ & $\begin{array}{l}180 \mathrm{~m}^{3} / \mathrm{h} \text { (inter.); } \\
150 \mathrm{~m}^{3} / \mathrm{h} \text { (cont.) }\end{array}$ \\
\hline Canada [CSA F326-M1989] & $180 \mathrm{~m}^{3} / \mathrm{h}$ (inter.; ex.) & $180 \mathrm{~m}^{3} / \mathrm{h}$ \\
\hline Portugal [NP 1037-2: 2009] & $\max (2 \times$ volume; $180 ; 216 \times$ stove width $) \mathrm{m}^{3} / \mathrm{h}$ (int.; ex.; MV) ${ }^{\mathrm{b}}$ & $216 \mathrm{~m}^{3} / \mathrm{h}$ \\
\hline Portugal [NP 1037-1: 2002] & $4 \mathrm{ACH}$ (cont.; ex.; NV) ${ }^{\mathrm{b}}$ & $120 \mathrm{~m}^{3} / \mathrm{h}$ \\
\hline
\end{tabular}

Notes. ex. - extraction; max. - maximum; inter. - intermittent; cont. - continuous; MV - mechanical ventilation; NV - natural ventilation.

a When there are type B combustion appliances and when the overall air flow rate exceeds $270 \mathrm{~m}^{3} /\left(\mathrm{h} \cdot 100 \mathrm{~m}{ }^{2}\right)$, a compensatory air inlet is required.

b It is necessary to predict the intake air flow rate for type A and B combustion appliances. 
this case, the ASHRAE 62.2: 2013 standard [25] requires operation at least once every $3 \mathrm{~h}$.

\subsection{Mixed ventilation systems in Portugal}

Often in Portugal natural and mechanical ventilation systems are associated with individual mechanical extraction in kitchens and natural extraction in bathrooms. The mechanical extraction is discontinuous, operating according to user needs and without their knowledge/control of extracted air flow rates.

Type B appliances should not be installed in places where there is exhaustion with mechanical ventilators as in Fig. 1 [26].

Disregard for this incompatibility often entails shutting the gas appliances down according to the reversal of the flow of combustion gases in the exhaust duct. Based on this finding, and in the context of a research project, we tried to experimentally assess the performance of the exhaust of combustion products in a naturally ventilated dwelling with a mechanical exhaust fan installed in the kitchen. In the following sections, the building, the dwelling where the test was conducted and the respective experimental results are presented. The chosen building was studied in the context of a wider research project for which results on the permeability of the components of the ventilation system and the dwellings have already been presented [27].

\section{Description of the building and ventilation system tested}

A four-storey multifamily building located in a neighborhood of Porto was chosen (Fig. 2). The flats had a ceiling height of approximately $2.5 \mathrm{~m}$. The natural ventilation system proposed by the designer had the following characteristics and locations (Fig. 3) [27]:

- self-adjustable air inlet device located above the roller shutter box at an approximate height of $2 \mathrm{~m}$; one self-regulated air inlet per room (the characteristic air flow rate is $30 \mathrm{~m}^{3} / \mathrm{h}$ at the pressure difference of $20 \mathrm{~Pa}$; this is a so-called "module 30" air inlet) and two in the living-room;

- fixed air inlet device on the external kitchen door (with an adjoining balcony) installed in the lower part of the door; its overall size is $55(w) \times 16.5(h) \mathrm{cm}^{2}$ and the air permeability is $q=59.312 \Delta p^{0.513}\left[\mathrm{~m}^{3} / \mathrm{h}\right]$;

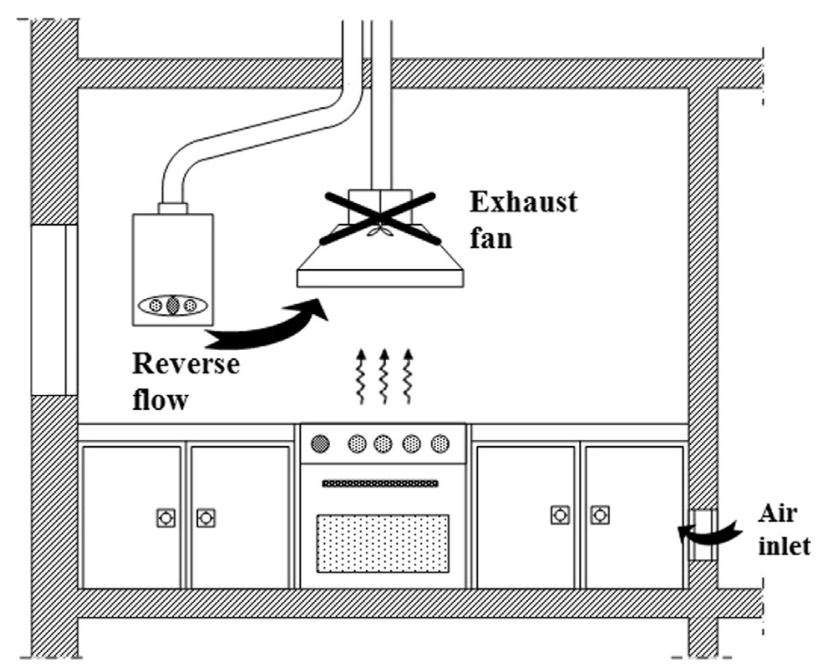

Fig. 1. Impossibility of combining mechanical extraction ventilation with natural ventilation (adapted from Ref. [26]).
- the air permeability of the external kitchen door is $q=5.446 \Delta p^{0.731}\left[\mathrm{~m}^{3} / \mathrm{h}\right]$

- the internal doors of the kitchen and bathroom have passage air inlets with an air permeability of $q=76.732 \Delta p^{0.50}\left[\mathrm{~m}^{3} / \mathrm{h}\right]$, according to the manufacturer;

- the air permeability of the internal kitchen door is $q=13.057 \Delta p^{0.602}\left[\mathrm{~m}^{3} / \mathrm{h}\right]$;

- natural extraction from bathroom with a fixed aluminum air outlet with an air permeability of $q=31.727 \Delta p^{0.50}\left[\mathrm{~m}^{3} / \mathrm{h}\right]$, according to the manufacturer; the bathroom duct has a diameter of $\phi 110$ and is insulated with $3 \mathrm{~cm}$ of polyurethane; there is a static ventilator (cowl) at the top of the duct on the roof (the nominal value of head loss factor claimed by the manufacturer is $\xi=1.51$ );

- stove extraction by individual metal duct $(\phi 150)$ by natural or mechanical action, in accordance with the tests (mechanical exhaust fan installed in the duct, however, with the possibility of being active or inactive - max. $\left.500 \mathrm{~m}^{3} / \mathrm{h}\right)$;

- extraction of water heater $(\approx 19.1 \mathrm{~kW})$ by natural action, located in the laundry room (the laundry and kitchen form a common space - no door between them) by collective metal duct with $\phi 175$ and without individual branches.

The kitchen window area is $1.80(w) \times 1.10(h) \mathrm{m}^{2}$ with an air permeability of $q=1.4810 \Delta p^{0.645}\left[\mathrm{~m}^{3} / \mathrm{h}\right]$, according to local measurements. In the above air permeability results, the air flows from the outside to inside the flat - depressurization. The volumes of the tested flats were approximately $160 \mathrm{~m}^{3}$, the volume of the kitchen + laundry was $23.2 \mathrm{~m}^{3}$ and the volume of the bathroom was $9.2 \mathrm{~m}^{3}$ Fig. 3 shows the flat type, the location of the ventilation system inlets, outlets and the size of the ducts.

Fig. 4 shows the predictable flows in accordance with the devices installed.

The overall air permeability test of flat 1 was carried out in accordance with method B of EN 13829: 2000 [28]. The permeability $(n)$ in pressurization was $4.5 \mathrm{~h}^{-1}$, and depressurization was $5.7 \mathrm{~h}^{-1}$ [27].

\section{Sensitivity analysis of operating the water heater and mechanical exhaust}

In order to assess the influence of the water heater, operated simultaneously or not with kitchen's mechanical exhaust (installed in the stove's duct), several tests were carried out aimed at determining the air flow rates and temperatures in each duct (water heater, mechanical extraction-stove and bathroom). We also measured the temperature and relative humidity in the various rooms in the flat - the relative humidity is not presented since it is irrelevant to this study's conclusions. At the same time, the conditions of indoor air circulation were changed. Interior doors were closed/open; the bathroom and kitchen door air inlets were closed/open and the exterior kitchen air inlet was closed/open. The tests were carried out in a first floor flat (flat number 1 ).

The conditions for recording the variables were as follows:

- outdoor temperature: records spaced 1 min apart (Rotronic reference probes; $\pm 0.5 \mathrm{~K}$ uncertainty)

- wind direction and speed: $30 \mathrm{~s}$ averages of records spaced $6 \mathrm{~s}$ apart (data obtained $6 \mathrm{~m}$ above the roof, above flat 5; Young reference equipment; $\pm 2 \%$ accuracy of velocity; $\pm 5 \%$ accuracy of direction);

- indoor temperature, measured at the center of the rooms: records spaced $1 \mathrm{~min}$ (Rotronic reference probes; $\pm 0.5 \mathrm{~K}$ uncertainty); 


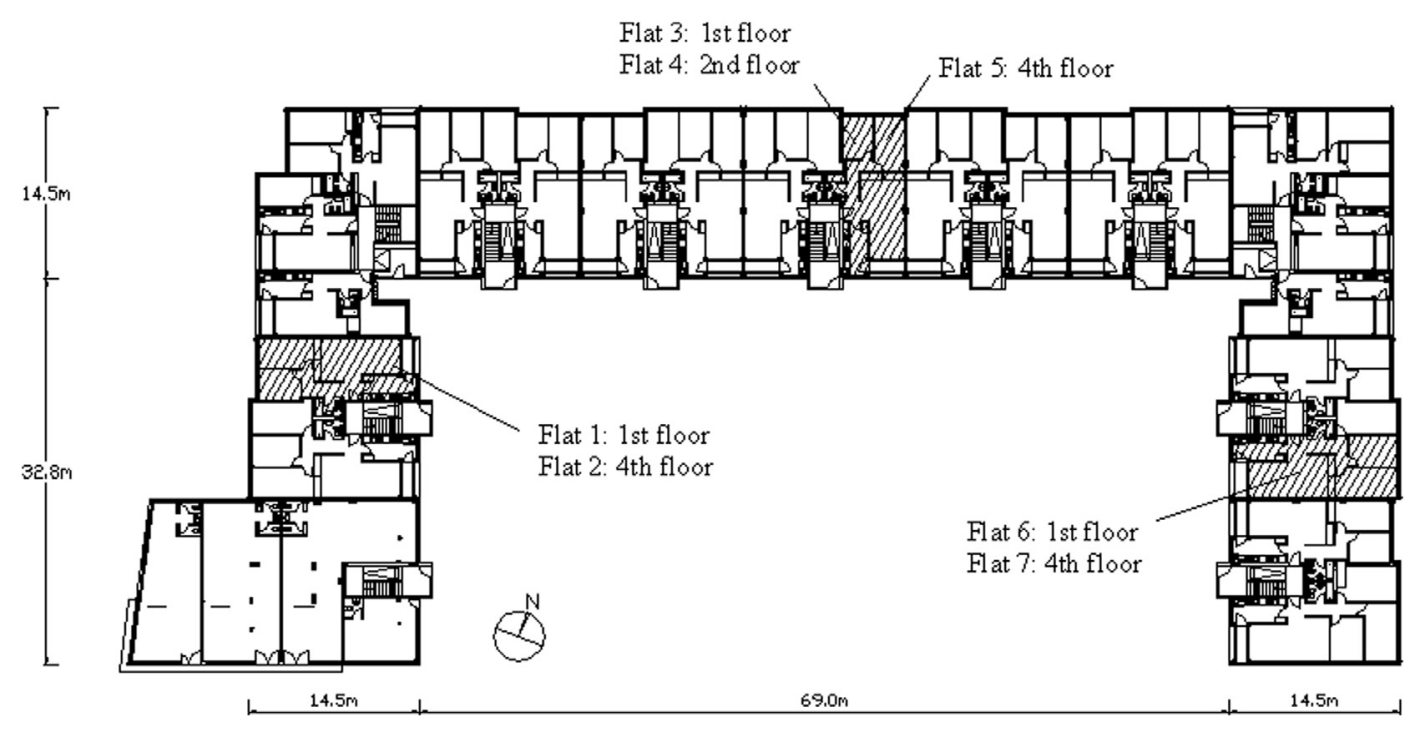

Fig. 2. Residential building containing the flats considered.

- temperature and velocity in the ducts: 20 s averages of records spaced $5 \mathrm{~s}$ apart; for the velocity of the stove the averages are taken $10 \mathrm{~s}$ apart (Airflow reference thermoanemometers, Ahlborn reference turbine Anemometers and type $\mathrm{T}$ and $\mathrm{J}$ thermocouples; uncertainty: temperature in ducts $\pm 1.8 \mathrm{~K}$; air flow rate in ducts $\pm 4.2 \mathrm{~m}^{3} / \mathrm{h}$ ).

Table 3 briefly presents the tests carried out in the sensitivity analysis.

The tests will be presented in chronological order. The conditions of the first test are described in Table 4.

The air flow rates registered in the various ducts, as well as the wind velocity, are shown in Fig. 5. One may conclude that the position of the doors or opening/closing the exterior air inlet of the kitchen does not interfere appreciably with the air flow rates (closing the exterior kitchen air inlet leads to a slight decrease of flow - Ref. (C) and the interior doors as well). It is worth noting that if the permeability of the envelope were reduced further, the position of the doors and closing of the exterior air inlet would probably have a greater influence.

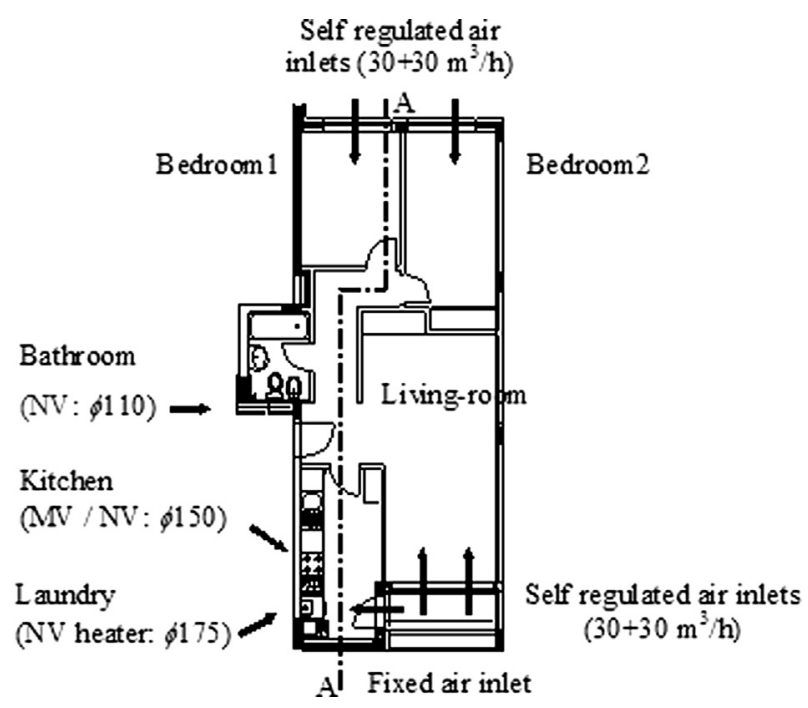

Fig. 3. Two-bedroom flat-ventilation system.
From the same figure, one may also conclude that the influence of wind velocity on the 1st floor is paramount to the increase of air flow rates in the stove and bathroom ducts (natural ventilation situation).

The predominant direction of wind was situated at the E-SE octants ( $83 \%$ of records) resulting in average pressure coefficients on the front facade of $0.22,-0.07$ on the rear facade and -0.83 on the roof. Despite the wind, the extracted air flow rates in the kitchen and bathroom are quite low, unlike the air flow rate extracted by the water heater duct. On average, we have an approximate extracted air flow rate of $75_{\text {heater }}+20_{\text {bath }}+20_{\text {stove }}=115 \mathrm{~m}^{3} / \mathrm{h}$, which leads to about $0.7 \mathrm{ACH}$ ( $4 \mathrm{ACH}$ in the kitchen and $2 \mathrm{ACH}$ in the bathroom). For the situation with the water heater stopped (the initial test), on average it can be deduced to have an approximate extracted air flow rate of $40_{\text {stove }}+20_{\text {bath }}+20_{\text {heater }}=80 \mathrm{~m}^{3} / \mathrm{h}$, which leads to about 0.5

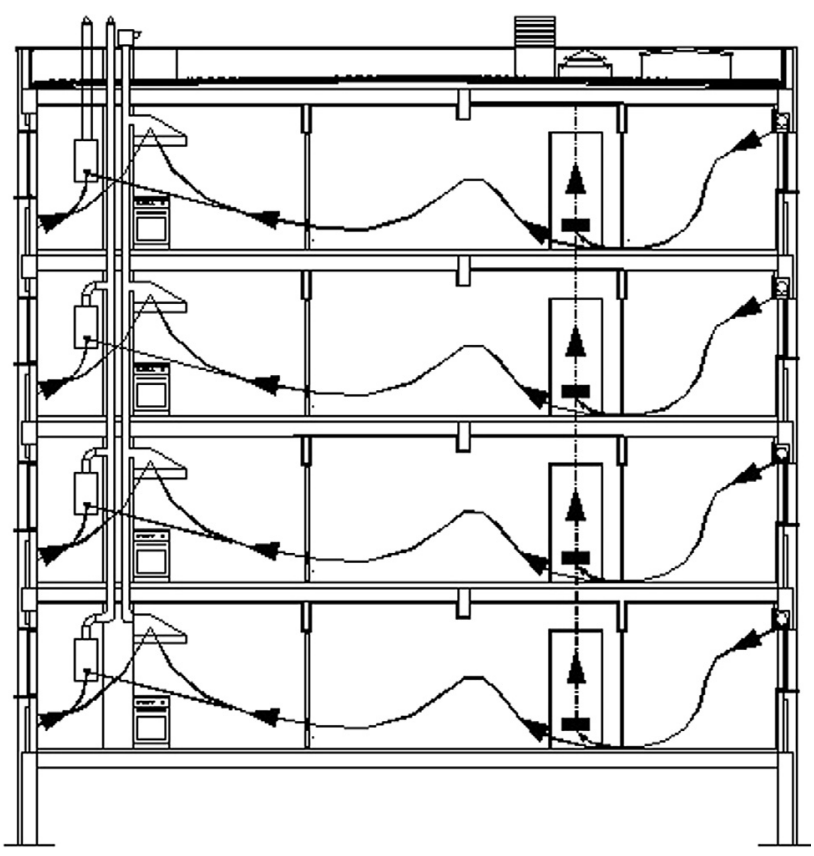

Fig. 4. Predictable flows. 
Table 3

Sensitivity analysis of operating water heater and mechanical/natural extraction. Summary of the tests performed.

\begin{tabular}{|c|c|c|c|c|c|}
\hline Ref. & $\begin{array}{l}\text { Stove exhaust } \\
\text { activated (1)? }\end{array}$ & $\begin{array}{l}\text { Hot water heater } \\
\text { activated }(2) ?\end{array}$ & $\begin{array}{l}\text { Interior doors } \\
\text { open (3)? }\end{array}$ & $\begin{array}{l}\text { Kitchen exterior } \\
\text { air inlet open (4)? }\end{array}$ & $\begin{array}{l}\text { Interior passage air } \\
\text { inlet open (5)? }\end{array}$ \\
\hline \multicolumn{6}{|l|}{1 st test } \\
\hline A & No & Yes & Yes & Yes & Yes \\
\hline B & No & Yes & No & Yes & Yes \\
\hline C & No & Yes & No & No & Yes \\
\hline $\mathrm{D}$ & No & Yes & Yes & No & Yes \\
\hline \multicolumn{6}{|l|}{ 2nd test } \\
\hline E & Yes & Yes & No & No & No \\
\hline 3rd test & & & & & \\
\hline $\mathrm{F}$ & No & Yes & Yes & Yes & Yes \\
\hline G & Yes & Yes & Yes & Yes & Yes \\
\hline \multicolumn{6}{|l|}{ 4th test } \\
\hline & No & No & Yes & Yes & Yes \\
\hline \multicolumn{6}{|l|}{ 5th test } \\
\hline I & Yes & Yes (2nd floor) & No & No & Yes \\
\hline
\end{tabular}

$\mathrm{ACH}$ ( $3 \mathrm{ACH}$ in the kitchen and $2 \mathrm{ACH}$ in the bathroom). Without the water heater duct we would only have whole only $40 \mathrm{~m}^{3} / \mathrm{h}(0.3$ $\mathrm{ACH}$ ) overall. The air flow rates extracted at the stove (similar air flow rates to bathroom, although the diameter of the stove duct being considerably greater) were obtained with the exhaust fan placed, highlighting this device pressure loss when it is stopped, and the respective significant restriction of the extracted air flow rates.

Fig. 6 presents the evolution of the temperature inside the rooms and Fig. 7 shows the evolution of the exterior temperature along with the temperatures in water heater and stove duct.

Analysis of Fig. 6 allows us to conclude that, despite the existence of passage air inlets, temperatures tend to rise in the rooms when doors are closed. This can lead to the conclusion that in a normal situation (bathroom door open simultaneously with the hot water running) the heat dissipates throughout all of the rooms. Closing the exterior kitchen air inlet leads to a slight decrease in temperature within the respective room. The explanation for this may be that the air feeding the water heater came from the exterior. It had an average temperature of $29.3^{\circ} \mathrm{C}$ from the beginning of the test, a temperature significantly higher than the kitchen's initial temperature.

Analysis of Fig. 7 shows cooling in duct between the 1st and 3rd floor water heater depending on the intake of new air from the 2 nd and 3rd floor kitchens since this is a collective duct. The temperature on the 3rd floor was very close to the exterior temperature which reduces the potential of the chimney effect.

The conditions of the second test are described in Table 5 .

The air flow rates recorded in the various ducts as well as the wind velocity are shown in Fig. 8. From this, we can conclude that the stove exhaust (maximum air flow rate of $180 \mathrm{~m}^{3} / \mathrm{h}$ ) interferes with the air flow rate extracted from the water heater (opposing peaks). From the same graph, we can also conclude that the influence of the wind speed at the 1st floor (where the mechanical ventilation is situated) is felt and the air flow rates extracted in the

Table 4

Sensitivity analysis of operating the exhaust fan to the position of interior doors and ventilation air inlets. Test with exhaust fan off and water heater on (natural ventilation).

\begin{tabular}{|c|c|}
\hline Time (Ref.) & Test conditions: 1 st test \\
\hline 11:06 (A) & $\begin{array}{l}\text { - Exhaust fan placed but not activated; } \\
\text { - Water heater activated (hot water in the bathroom); } \\
\text { - Interior doors open; } \\
\text { - Interior passage air inlets open. } \\
\text { - Kitchen exterior air inlet open. }\end{array}$ \\
\hline $11: 21$ & - End of test. \\
\hline $11: 24(\mathrm{~B})$ & - Interior doors closed (3). \\
\hline $11: 39$ & - End of test. \\
\hline $11: 41(\mathrm{C})$ & - Exterior kitchen air inlet closed (4). \\
\hline $11: 56$ & - End of test. \\
\hline $11: 57(\mathrm{D})$ & - Interior doors open (3). \\
\hline $12: 13$ & - End of test. \\
\hline
\end{tabular}

Indication of elements which vary their position/operation during the test (Section AA)

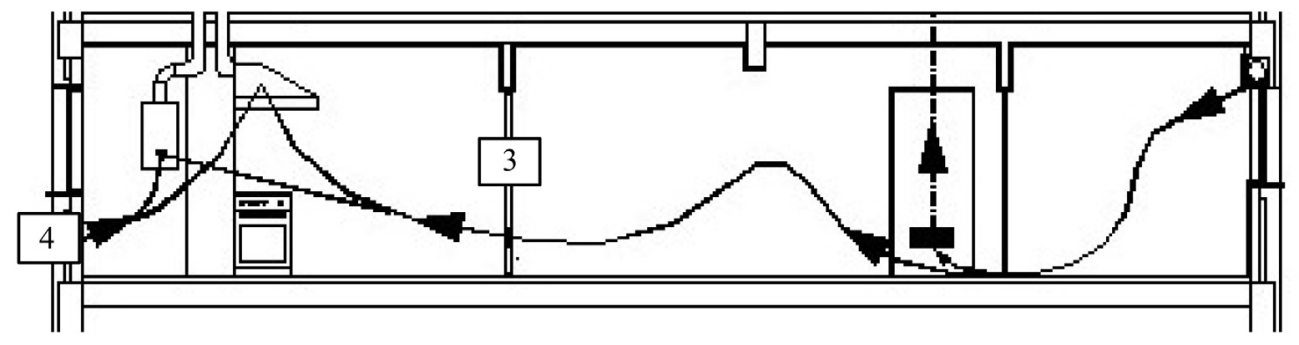



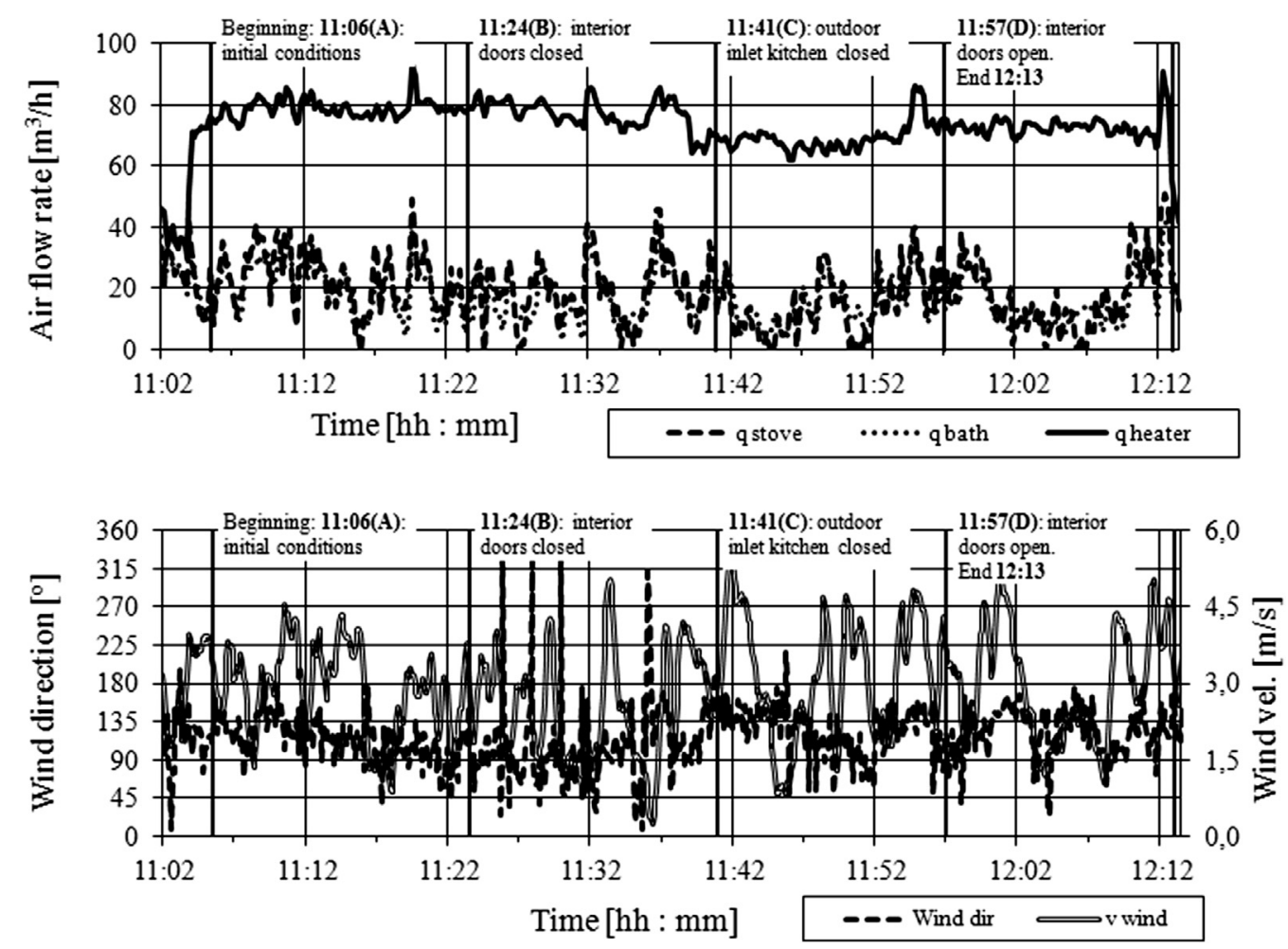

Fig. 5. Sensitivity analysis of operating the water heater relative to the position of interior doors and ventilation air inlets. Air flow rates, wind speed and direction for the test with exhaust fan off and water heater on (natural ventilation).

bathroom are low with an average air flow rate of $10 \mathrm{~m}^{3} / \mathrm{h}(1 \mathrm{ACH})$, relative to natural ventilation (first test), and they suffer a slight influence from the exhaust fan.

In Fig. 9 the likely time the water heater was stopped by the safety device ( $\approx 12: 57$ ) can be observed as there is a simultaneous reduced water heater extraction air flow rate (less than the start of the test) and the beginning of the temperature decrease in the respective duct (probable intake of new exterior air). According to NP EN 297: 1998 [29], the maximum amount of time to the stop the water heater is 2 or $8 \mathrm{~min}$, depending on the presence of a complete or partial obstruction respectively. In this case, in view of the operating time of the exhaust fan with higher air flow rates $(\approx 12: 49-12: 57)$, the extraction by the stove duct functions as a partial obstruction.
Thus, we can conclude that the obstruction of the supply of the water heater air inlet together with the mechanical extraction of the combustion products of the stove provide strong contributions to the malfunctioning of the water heater - this situation closely resembles the anomalies often recorded in residential dwellings in Portugal.

The conditions for the third test are described in Table 6 .

The air flow rates registered in the various ducts as well as the wind velocity are shown in Fig. 10. It appears that in the position of everything open (interior doors and kitchen exterior air inlet opened), the sharp increase in the extracted air flow rate by the exhaust fan (maximum air flow rate of approximately $380 \mathrm{~m}^{3} / \mathrm{h}$ ) interferes slightly with the air flow rate extracted by the water heater (decrease over time). Fig. 10 also leads to the conclusion that the influence of the wind speed at the 1st floor (situation of

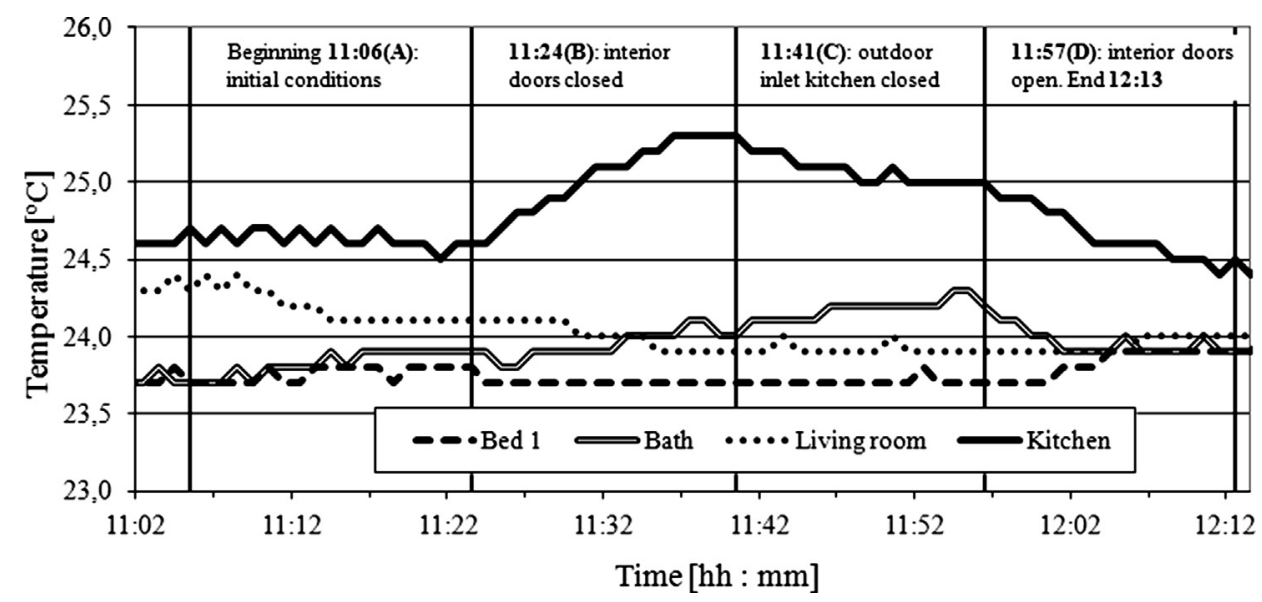

Fig. 6. Sensitivity analysis of operating the water heater relative to the position of interior doors and ventilation air inlets. Temperature in the rooms for the test with exhaust fan off and the water heater on (natural ventilation). 


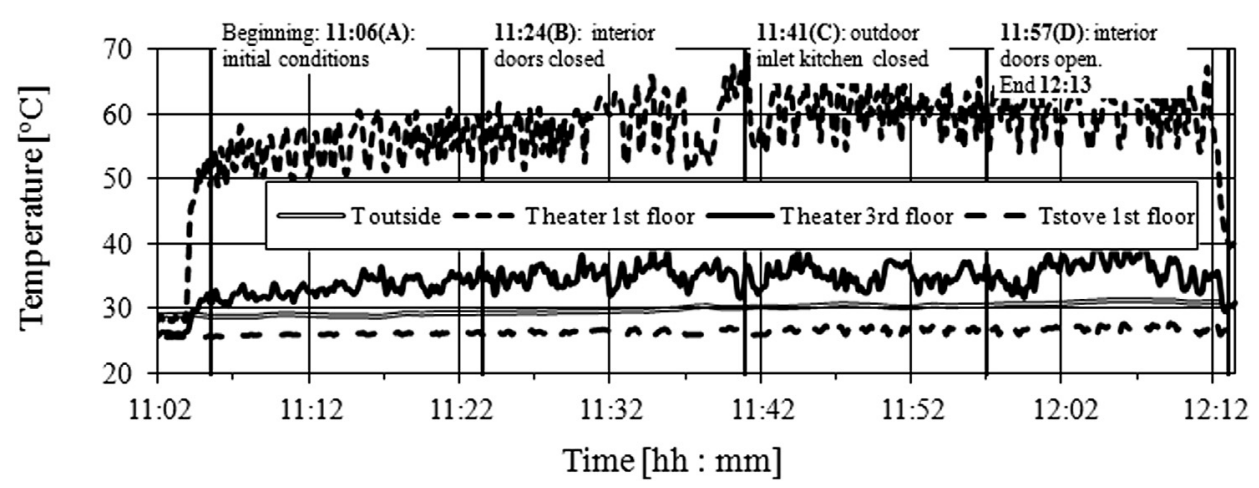

Fig. 7. Sensitivity analysis of operating the water heater relative to the position of interior doors and ventilation air inlets. Exterior temperature and temperatures of water heater and stove ducts for the test with exhaust fan off and water heater on (natural ventilation).

mechanical ventilation) is not felt and the air flow rates extracted in the bathroom are low, average air flow rate of $10 \mathrm{~m}^{3} / \mathrm{h}$, relative to natural ventilation (first test).

A comparative analysis between the last two tests reveals that there is greater interference of the exhaust fan on the air flow rates of the water heater and bathroom duct in the situation with everything closed (second test). In the third test, although the air flow rate of the water heater extraction is reduced, it is not enough to activate the safety device. In this case, we have a air flow rate in the exhaust fan which is approximately twice as high as in the second test highlighting the importance of the air intake conditions to the water heater. Comparing the three tests, we concluded that the action of the wind, while significant, is only paramount in the case of the system with just natural ventilation (first test).

The conditions of the fourth test are described in Table 7.

Air flow rates recorded in the various ducts as well as the wind speed are shown in Fig. 11. As in the first test (natural ventilation conditions), we can also conclude that the influence of the wind speed at the 1 st floor is paramount to the increase in stove duct air flow rates. The predominant direction stood at octants SW-W $(81 \%$ of records; the average pressure coefficients are negative). However, in the bathroom air flow rates do not suffer the same increase due to the wind speed. On average, the extracted stove and bathroom air flow rates are slightly lower than those of the first test (in this case $10 \mathrm{~m}^{3} / \mathrm{h}$ ). The extracted air flow rate in the water heater duct was not measured due to an anemometer malfunction.

If we assume that the extracted air flow rate in the water heater duct is on average of the same order of that measured at the beginning of the first and second tests, we have an extracted air flow rate of approximately $50_{\text {heater }}+10_{\text {stove }}+10_{\text {bath }}=70 \mathrm{~m}^{3} / \mathrm{h}$, which overall leads to about $0.4 \mathrm{ACH}$ ( $3 \mathrm{ACH}$ in the kitchen and 1 $\mathrm{ACH}$ in the bathroom). This $\mathrm{ACH}$ is substantially less than the 0.7 $\mathrm{ACH}$ obtained in the first test with water heater on. It is worth noting that air flow rates extracted on the stove were obtained with the exhaust fan in place.

The conditions of the fifth test are described in Table 8 .

In this test the water heater was on in the 2nd floor kitchen and the mechanical exhaust fan with increasing air flow rate was also activated in the 1st floor kitchen. At 17:07 for an exhaust air flow rate of approximately $450 \mathrm{~m}^{3} / \mathrm{h}$, the pressure inside the 1 st floor kitchen is sufficiently low to reverse the flow of combustion products from the 2 nd to the 1 st floor, as the temperature in the combustion exhaust duct of the 1 st floor increased severely (up to about $58^{\circ} \mathrm{C}$ ), as shown in Fig. 12 .

Table 5

Sensitivity analysis of operating the exhaust fan relative to the water heater (everything closed).

\begin{tabular}{ll}
\hline Time (Ref.) & Test conditions: 2nd test \\
\hline $12: 32$ & - Exhaust fan placed; \\
& - Interior doors closed; \\
& - Interior passage air inlets closed; \\
& - Exterior kitchen air inlet closed. \\
$12: 34$ & - Water heater on (hot water in the bathroom) (2). \\
$12: 38(E)$ & - Exhaust fan on (1). \\
$12: 43$ & - Increase in exhaust fan speed (1). \\
$12: 47$ & - Increase in the exhaust fan (there were variations in the exhaust fan between $12: 50$ and12:55) (1). \\
$12: 55$ & - End of test (the water heater stopped as a result of its safety mechanism). \\
Indication of the elements whose position/operation vary during the test (Section AA)
\end{tabular}

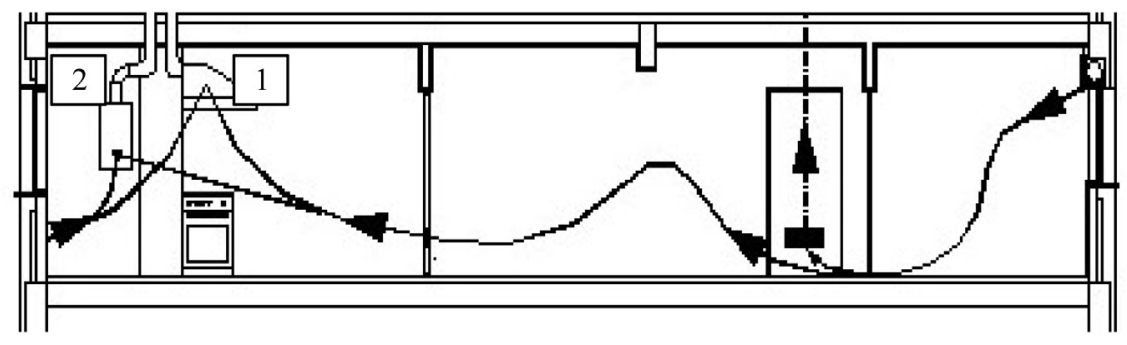




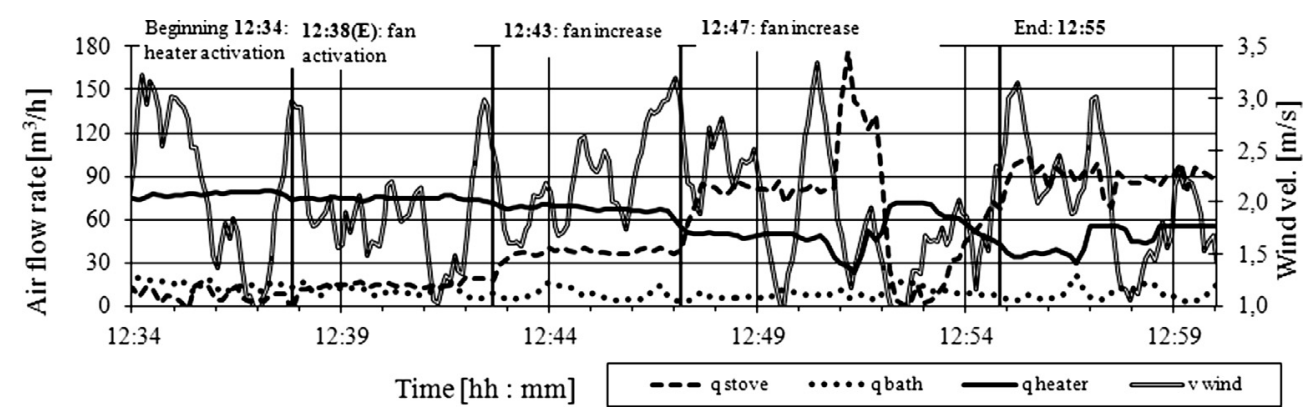

Fig. 8. Sensitivity analysis of operating the exhaust fan relative to the water heater. Air flow rates and wind speed (everything closed).

This test shows that activating the mechanical ventilation in flats with natural ventilation (provided they are interconnected by collective ducts) can create hazardous conditions due to the reverse flow of the combustion products. Note that this risk is not detectable by the type B appliance's safety device since no restriction to the exhaust air flow rate occurs; there is only a change in the flow path. Although this situation is found for a rather high air flow rate (about $450 \mathrm{~m}^{3} / \mathrm{h}$ ), it is demonstrative of what can happen in mixed ventilation systems in Portugal, as the existing exhaust fans typically have equivalent or even higher maximum air flow rates.

Below are the main conclusions drawn from the tests.

As for the position of doors and passage air inlets, the following can be concluded:

- closing the interior doors of the kitchen and bathroom, regardless of whether or not the respective doors have passage air inlets, it is essential to avoid spreading water vapor and heat generated in the respective rooms (1st test);

- in the case of natural ventilation, the position of the doors and exterior air inlet does not considerably influence the extracted air flow rates (1st and 2nd tests);

- in the case of mechanical exhaust in the kitchen, the exterior kitchen air inlet can be a good aid to the water heater extraction and may have obviated the air flow reversals in the bathroom; nevertheless, the air admitted directly into the kitchen does not flow out through the other rooms, so that it does not contribute to ventilating them (3rd test).

Regarding the influence of wind speed, the following can be concluded:

- in the case of natural ventilation, wind speed has paramount influence, at least on the 1st floor, in the extraction by the stove and bathroom ducts (1st and 4th tests);

- mechanical exhaust is less sensitive to the influence of wind speed (2nd and 3rd tests).
Concerning the flow and ventilation rates obtained, the following can be concluded:

- in the case of natural ventilation, the extracted air flow rates are low, approximately $0.40-0.50 \mathrm{ACH}$ (with the exhaust fan placed and the water heater off). When the water heater was operating, there is an increase in the extracted air flow rates, approximately $0.70 \mathrm{ACH}$ (1st test);

- the average extracted air flow rates in the bathroom are quite low $\left(10-20 \mathrm{~m}^{3} / \mathrm{h}\right)$ (1st to 4 th test),

- in the case of mechanical exhaust, the extracted air flow rates of the water heater and the bathroom are influenced by it (2nd, 3rd and 5th tests).

As for the influence of the exhaust fan, the following can be concluded:

- in the position of everything closed (doors and air inlets), the exhaust fan interferes with the extracted air flow rates from the water heater and the possibility of stopping it by activating its safety device exists. The extracted air flow rates in the bathroom are lower than in the natural ventilation situation (1st and 5th tests);

- in extreme cases (high air flow rates and closed exterior outside kitchen air inlets) reverse flow of the combustion products may occur, including from floors above the mechanical exhaust fan (5th test);

- in the position of everything open (doors and air inlets), the influence of the exhaust fan is smaller in relation to the previous situation, even for high air flow rates (3rd test).

\section{Recommendations for the coexistence of type $B$ and mechanical exhaust in the same space}

The coexistence of type B combustion devices (water heaters or boilers where combustion air is captured directly at the installation) with mechanical exhaust fans is not recommended. This

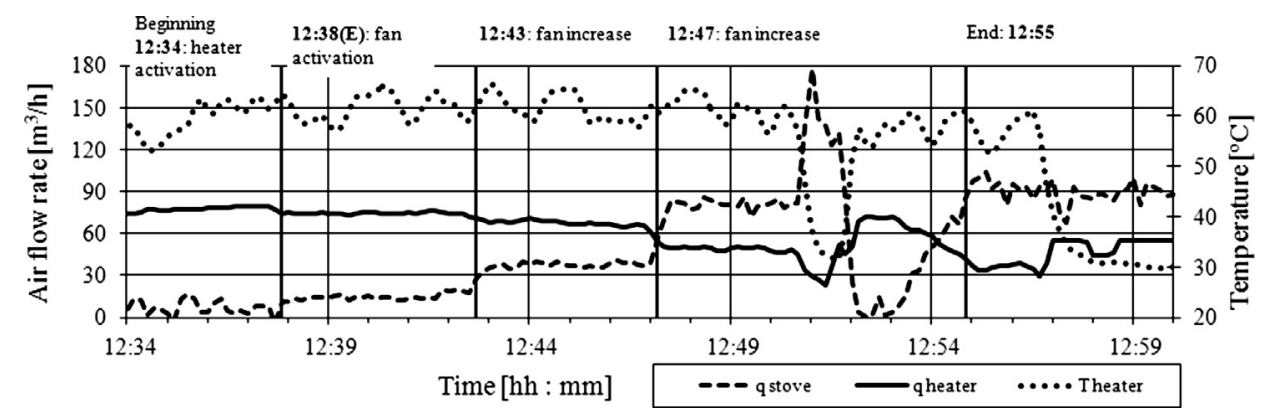

Fig. 9. Sensitivity analysis of operating the exhaust fan relative to the water heater. Air flow rates and temperature of the duct water heater (everything closed). 
Table 6

Sensitivity analysis of operating the exhaust fan relative to the water heater (everything open).

\begin{tabular}{|c|c|}
\hline Time (Ref.) & Test conditions: 3 rd test \\
\hline $13: 02(F)$ & $\begin{array}{l}\text { - Exhaust fan placed; } \\
\text { - Water heater activated (hot water in bathroom); } \\
\text { - Interior doors open; } \\
\text { - Interior passage air inlets open; } \\
\text { - Exterior kitchen air inlet open. }\end{array}$ \\
\hline $13: 08$ & - Exhaust fan off. \\
\hline $13: 13(G)$ & - Exhaust fan on (1). \\
\hline $13: 17$ & - Exhaust fan operating (1). \\
\hline $13: 22$ & - Increase in exhaust fan speed (1). \\
\hline $13: 26$ & - Increase in exhaust fan speed (1). \\
\hline $13: 31$ & - Increase in exhaust fan speed (1). \\
\hline $13: 35$ & - Increase in exhaust fan speed (1). \\
\hline $13: 39$ & - Increase in exhaust fan speed (1). \\
\hline $13: 42$ & - Increase in exhaust fan speed (1). \\
\hline $13: 46$ & - Increase in exhaust fan speed (1). \\
\hline $13: 50$ & - End of test. \\
\hline
\end{tabular}

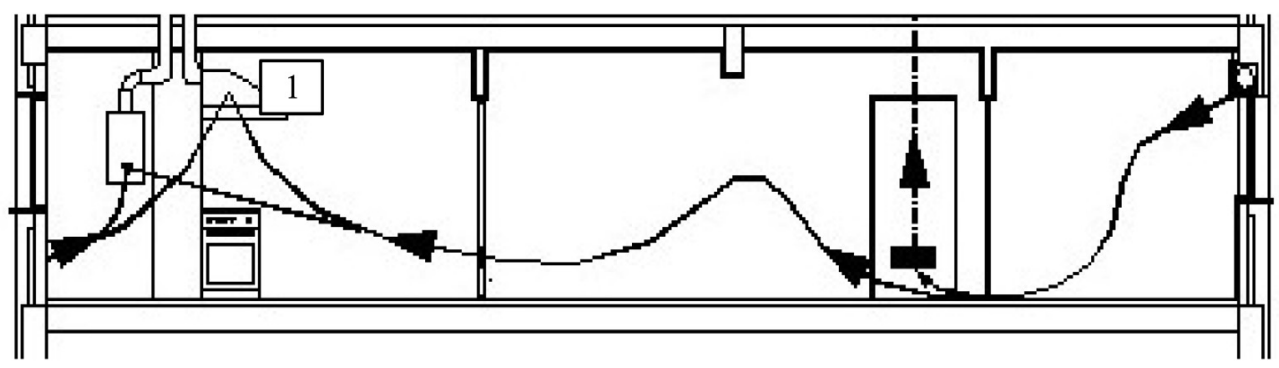

situation can produce a significant depression in the kitchen and prevent the operation of type $B$ appliances (2nd test) or reverse the direction of flow of combustion products in the natural evacuation duct (5th test). Nevertheless, this coexistence can be resolved as follows:

- type B device installed in an exterior location to the heated space with its own ventilation system, for example in laundries (preferred solution),

- using type $\mathrm{C}$ appliances (independent intake and exhaust); they must have vertical extraction ducts leading to the roof;

- using of a "discriminating" mechanism to prevent the simultaneous operation of the combustion appliance and mechanical exhaust:
- using electrical appliances for domestic hot water or to heat the indoor environment;

- including an air inlet in the kitchen which must be sized to admit compensation air when the combustion appliance and mechanical exhaust fan are being operated simultaneously.

With regards to this last solution, the opening of the intake should be sized to admit compensation air (maximum air flow rate subtracted from the base air flow rate), adjustable (non- closing) and should only come into operation for maximum air flow rates (during meal preparation, see Table 2) so as not to interfere with the normal air flow rates of base ventilation. The characterization of this supplemental air intake situated preferentially in the same place as the type B appliance is specified in several documents:

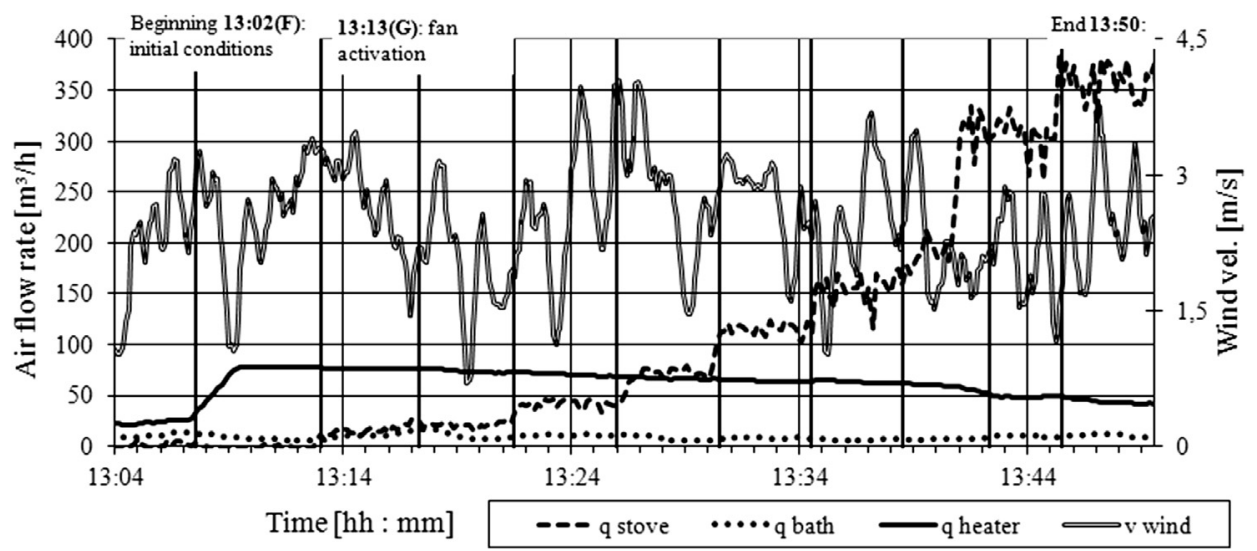

Fig. 10. Sensitivity analysis of operating the exhaust fan relative to the water heater. Air flow rates and wind speed (everything open). 
Table 7

Sensitivity analysis with the devices off (natural ventilation).

\begin{tabular}{ll}
\hline Time (Ref.) & Test conditions: 4th test \\
\hline $14: 00(\mathrm{H})$ & - Exhaust fan placed but not activated; \\
& - Water heater off; \\
& - Interior doors open; \\
& - Interior passage air inlets open; \\
& - Exterior kitchen air inlet open. \\
$15: 03$ & - End of test. \\
\hline
\end{tabular}

- standard ASHRAE 62.2: 2013 which recommends its implementation for an overall extraction air flow rate greater than $270 \mathrm{~m}^{3} /\left(h \cdot 100 \mathrm{~m}^{2}\right)[25]$;

- in Belgium this supplemental air inlet is recommended to be sized for a pressure difference of $5 \mathrm{~Pa}$, resulting in approximately $160 \mathrm{~cm}^{2}$ per $100 \mathrm{~m}^{3} / \mathrm{h}$ of extraction air flow rate as well as the use of adjustable air inlets to allow closure when the mechanical exhaust is not functioning [30].

With mechanical exhaust and without type B appliances, several prototypes of self-regulating air inlets have already been developed. They open at the high pressures (30 Pa) to allow air to enter the kitchen directly when there are extreme air flow rates [31]. Admission of these air flow rates by the main rooms is thereby avoided with the potential problems of oversizing air intake and comfort. In intermittent systems, an air inlet sized for $\Delta p=10 \mathrm{~Pa}$ is recommended [30].

The maximum extracting air flow rate should not exceed the limits stated in Table $2\left(\approx 200 \mathrm{~m}^{3} / \mathrm{h}\right)$. The English regulation is the strictest imposing a maximum air flow rate of $72 \mathrm{~m}^{3} / \mathrm{h}$ in kitchens with mechanical extraction and boiler [32]. Nevertheless, certainly to avoid possible contamination from pollutants, ASHRAE 62.2: 2013 establishes that $\mathrm{CO}$ detectors must be placed in homes [25].

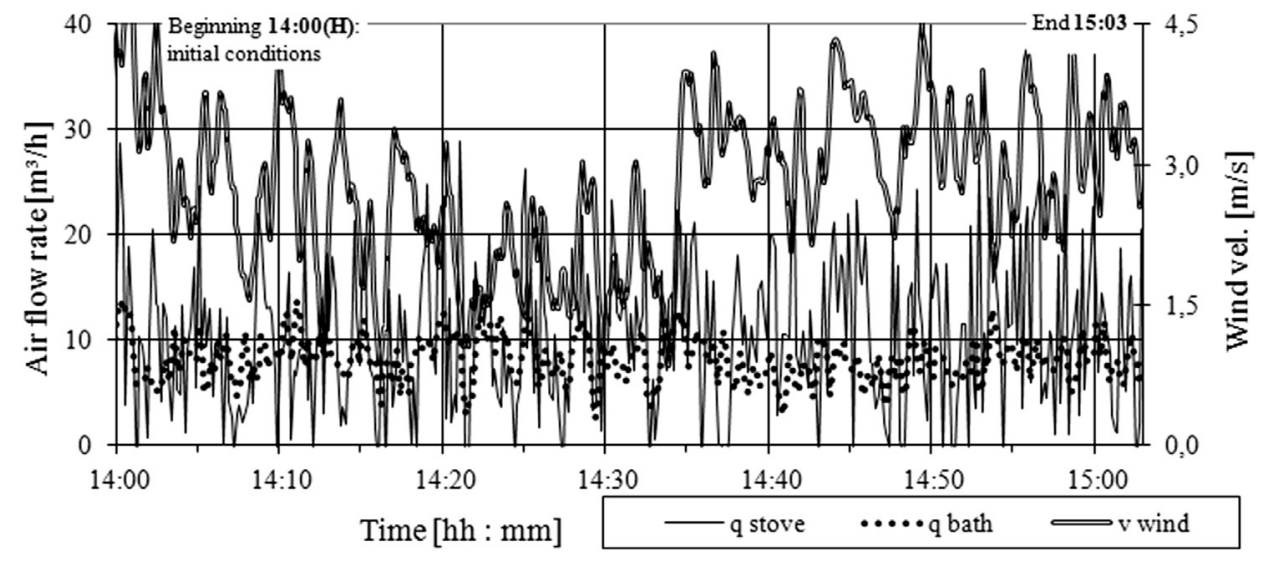

Fig. 11. Sensitivity analysis with the devices off. Air flow rates and wind speed (natural ventilation).

Table 8

Sensitivity analysis of operating the exhaust fan relative to the water heater on the 2nd floor (exterior kitchen air inlets closed).

\begin{tabular}{|c|c|}
\hline Time (Ref.) & Test conditions: 5 th test \\
\hline $16: 45(\mathrm{H})$ & $\begin{array}{l}\text { - 1st floor water heater off; } \\
\text { - 2nd floor water heater on (hot water in the bathroom); } \\
\text { - Interior doors closed; } \\
\text { - Interior passage air inlets open; } \\
\text { - Exterior kitchen air inlet closed in the 1st and 2nd floor; } \\
\text { - Exhaust fan off. }\end{array}$ \\
\hline $16: 48$ & - 1st floor kitchen exhaust fan on (1). \\
\hline $16: 51$ & - Increase in exhaust fan speed (1). \\
\hline $16: 54$ & - Increase in exhaust fan speed (1). \\
\hline $16: 57$ & - Increase in exhaust fan speed (1). \\
\hline 17:02 & - Increase in exhaust fan speed (1). \\
\hline $17: 07$ & - Increase in exhaust fan speed (1). \\
\hline $17: 12$ & - End of test. \\
\hline
\end{tabular}

Indication of the elements whose position/operation vary during the test (Section AA)

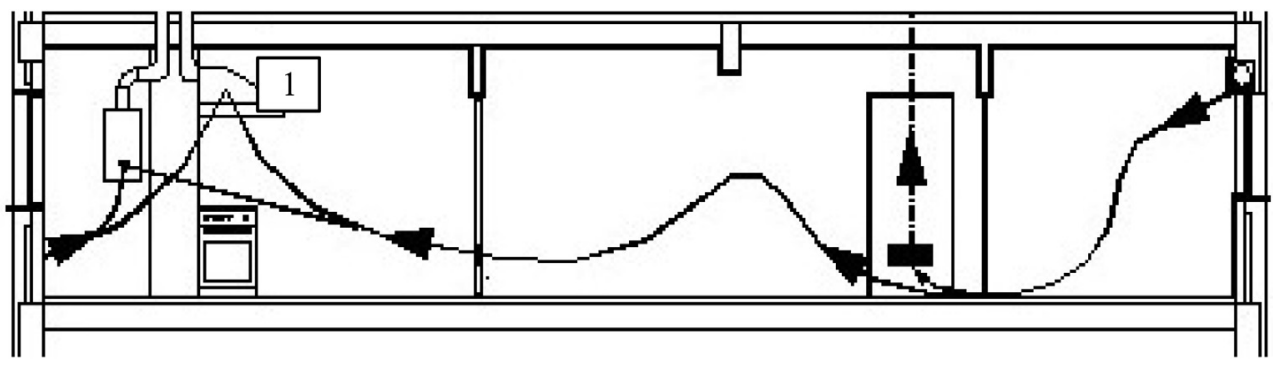




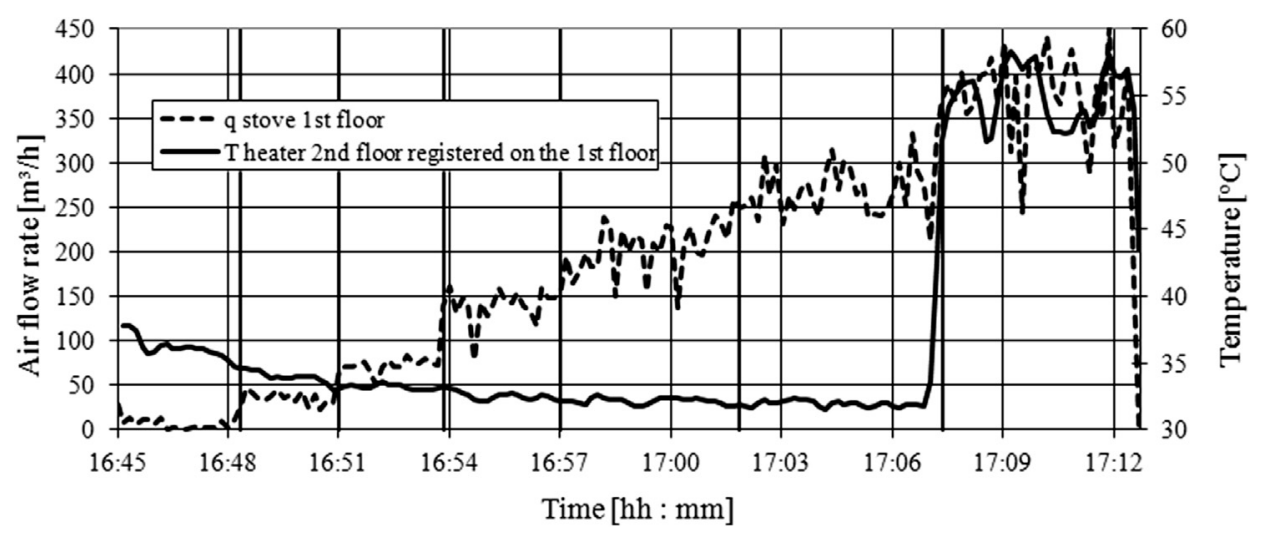

Fig. 12. Sensitivity analysis of operating the exhaust fan relative to the water heater on the 2nd floor. Air flow rate and temperature, respectively, in the stove and water heater ducts (exterior kitchen air inlets closed).

\section{Conclusions}

The field tests showed that the combination of natural ventilation with mechanical ventilation in spaces interconnected by ducts may lead to dangerous situations when type $B$ gas appliances water heating are used (for a $20 \mathrm{~kW}$ nominal power gas appliance). The most serious cases were recorded in the following situations, under the conditions described in this paper:

- safety stop of type B device when the mechanical exhaust was of the order of $180 \mathrm{~m}^{3} / \mathrm{h}$ with doors and interior passage and kitchen air inlet closed;

- reverse flow of combustion products of the type B appliance when the mechanical exhaust was of the order of $450 \mathrm{~m}^{3} / \mathrm{h}$ with interior doors and kitchen air inlet closed and the interior passage air inlets open.

Quite often in Portugal people install exhaust fans mechanics supposedly in order to improve the ventilation system in their dwellings. The tests showed that this can have a negative impact on the performance of type B water heating gas appliances in their homes and in the flats above or below them served by the same collective natural ventilation duct. This impact will be more serious for dwellings with low air permeability (more common in new dwellings) and may result in releasing pollutants into the home.

As a general recommendation for new buildings, implementing appropriately sized natural ventilation systems and preventing people installing mechanical ventilators is advised. If there is a risk of people installing mechanical ventilators later installation by users, type $\mathrm{C}$ appliances are recommended or type $\mathrm{B}$ appliances in a location exterior to the heated space, such as in laundries, with their own ventilation system. If there are constraints in terms of physical space or in the case of renovation, an air inlet is recommended in kitchens. It should be sized so as to admit compensation air; it should adjustable and should only be activated for maximum air flow rates. Its existence has the disadvantage that, while it is open, reducing ventilation air flow rates from other the rooms will be reduced.

\section{Acknowledgments}

This research was supported by the Fundação para a Ciência e Tecnologia (Research Project POCTI/ECM/45555/2002).

\section{References}

[1] CEN. European scheme for the classification of gas appliances according to the method of evacuation of the combustion products (types). PD CEN/TR 1749. Brussels, Belgium: European Committee for Standardization.
[2] Viegas J, Pinto M, Pinto A. The influence of ventilation in the work of domestic combustion appliances. Helsinki, Finland: Proceedings of 10th Roomvent conference; 2007.

[3] Tam C, Bevan R, Harrison P, Youngs L, Crump D. Public health impacts of exposure to carbon monoxide from gas appliances in UK homes - are we missing something? Indoor Built Environment 2012;21:229-40.

[4] Zorraquino J, Diaz V, San José R. Indoor air quality problems and solutions in the Basque country (Spain) related to natural and/or liquid petroleum gas usage in individual heating installations. Indoor Environment 1994;3:286-91.

[5] Borchiellini R, Cali M, Girard M, Masoero M. The influence of purposeprovided openings on natural ventilation of buildings equipped with gas fired appliances. Denmark, Copenhagen: Proceedings of 14th AIVC conference; 1993.

[6] Warren P, Webb B. Air supply for domestic combustion appliances. Building and Environment 1976;11:259-69.

[7] McWilliams J, Sherman M. Review of literature related to residential ventilation requirements. Annotated Bibliography 13, Annex 5-AIVC. Brussels, Belgium: IEA-ECBCS; 2007

[8] IPQ. Ventilation and combustion products evacuation from places with gasburning appliances. Part 1: Dwellings. In: Natural ventilation. Monte da Caparica, Portugal: Instituto Português da Qualidade; 2002 [in Portuguese]. NP 1037-1.

[9] Kirchner S, Derbez M, Duboudin C, Elias P, Garrigue J, Gregoire A, et al. Indoor air quality in French dwellings. Contributed Report 12, Annex 5-AIVC. Belgium: IEA-ECBCS; 2009.

[10] Logue J, Sherman M, Price P, Singer B. Why we ventilate. Brussels, Belgium: Proceedings of 32nd AIVC conference; 2011.

[11] Jantunen M, Oliveira Fernandes E, Carrer P, Kephalopoulos S. Promoting actions for healthy indoor air (IAIAQ). Luxembourg: European Commission Directorate General for Health and Consumers; 2011.

[12] Brelih N, Seppänen O. Ventilation rates and IAQ in european standards and national regulations. Brussels, Belgium: Proceedings of 32nd AIVC conference; 2011.

[13] WHO. Air quality guidelines. Globalupdate 2005. World Health Organization; 2005.

[14] WHO. Air quality guidelines: selected pollutants. Bonn: World Health Organization; 2010.

[15] EPA. National ambient air quality standards. Washington, DC, USA: U. S. Environmental Protection Agency; 2013. http://www.epa.gov/air/criteria.html.

[16] Dorer V, Pfeiffer A, Weber A. Parameters for the design of demand controlled hybrid ventilation systems for residential buildings. Technical note 59, Annex 5-AIVC. Brussels, Belgium: IEA-ECBCS; 2005.

[17] CEN. Ventilation for buildings. Design and dimensioning of residential ventilation systems. CEN/TR 14788. Brussels, Belgium: European Committee for Standardization; 2006.

[18] Trepte L, Haberda F. AIVC, IEA Annex IX. Minimum ventilation rates and measures for controlling indoor air quality. Technical Note 26, Annex 5-AIVC. Coventry, Great Britain: IEA-ECBCS; 1989.

[19] Avgelis A, Papadopoulos A. Indoor air quality guidelines and standards - a state of the art review. International Journal of Ventilation 2004:3:267-78.

[20] CEN. Indoor environmental input parameters for design and assessment of energy performance of buildings. EN 15251. In: Addressing indoor air quality, thermal environment, lighting and acoustic. Brussels, Belgium: European Committee for Standardization; 2007.

[21] Coward S, Raw G, Llewellyn J, Ross D. Indoor air quality in English homes nitrogen dioxide. Monterey. California, USA: Proceedings of 9th Indoor Air conference; 2002.

[22] Ross D. Computational investigation of ventilation strategies to reduce exposure to $\mathrm{NO}_{2}$ and $\mathrm{CO}$ from gas cooking. Reading, United Kingdom: Proceedings of 7th Roomvent conference; 2000.

[23] IPQ. Ventilation and combustion products evacuation from places with gasburning appliances. Part 2: Dwellings. In: Single flux centralised mechanica 
ventilation. Monte da Caparica, Portugal: Instituto Português da Qualidade; 2009 [in Portuguese]. NP 1037-2.

[24] Dimitroulopoulou C. Ventilation in European dwellings. A review. Building and Environment 2012;47:109-25.

[25] ASHRAE. Ventilation and acceptable indoor air quality in low-rise residential buildings. In: Ansi/Ashrae standard 62.2: 2013. Atlanta, USA: American Society of Heating, Refrigeration and Air-Conditioning Engineers; 2013.

[26] IPQ. Ventilation of buildings with gas appliances. Part 3.1: Installation of gas appliances: Volume from places; Position from gas appliances and their links to various power systems; connections to ventilation system. Monte da Caparica, Portugal: Instituto Português da Qualidade; 2012 [in Portuguese]. NP 1037-3-1.

[27] Pinto M, Viegas J, Freitas V. Air permeability measurements of dwellings and building components in Portugal. Building and Environment 2011;46:2480-9.
[28] CEN. Thermal performance of buildings. Determination of air permeability of buildings. In: Fan pressurization method. Brussels, Belgium: European Committee for Standardization; 2000. EN 13829.

[29] IPQ. Gas-fired central heating boilers. In: Type B11 and B11BS boilers fitted with atmospheric burners of nominal heat input not exceeding $70 \mathrm{~kW}$. Monte da Caparica, Portugal: Instituto Português da Qualidade; 1998 [in Portuguese]. NP EN 297.

[30] CSTC. Ventilation des cuisines et hottes aspirantes. Note d'Information Technique 187. Bruxelles, Belgique: Centre Scientifique et Technique de la Construction; 1993.

[31] Tip-vent. Towards improved performances of mechanical ventilation systems. In: Tip-vent source Book 2001. EU programme: Non Nuclear Energy Programme Joule IV.

[32] Stationary Office. The building regulations 2010-combustion appliances and fuel storage systems. Approved Document J. London, UK; 2010. 